\title{
An Analysis of the Vibration Characteristics of Automotive Exhaust Systems and Optimization of Suspension Points
}

\author{
Jian Min $\mathrm{Xu}^{*}$, Shuiting Zhou and Shui xuan Chen
}

\author{
School of Mechanical and Automotive Engineering, Xiamen University of Technology, Xiamen, 361024, P.R. China
}

\begin{abstract}
In order to reduce the impact of automotive exhaust systems on the vehicle vibration, finite element modal analyses of the exhaust system of a motor vehicle are conducted in its natural state, partially constraints state and fully constraints state. The natural frequencies and mode shapes of the exhaust system are obtained. The harmonic analysis is conducted on the basis of the modal analysis. The results show that: the vibration amplitude of the exhaust system at lowspeed operating condition is relatively bigger than that of the exhaust system in high-speed conditions. The excitation frequency of the engine at the idle and economy speed can avoid the natural frequency of the exhaust system, so it can be stated that the system has good dynamic characteristics. Suspension points on the exhaust system are optimized and the optimal mounting points are located based on the method of the average drive DOF displacement (ADDOFD). The study has practical significance for reducing the vibration of automobile exhaust systems and the vehicle.
\end{abstract}

Keywords: Automotive exhaust system, hanging position, harmonic analysis, modal analysis.

\section{INTRODUCTION}

Automobile exhaust system is a vibration system with multiple degrees of freedom. Its vibration input source includes the vibration generated by the engine and the road vibration. At first, the engine is directly connected to the exhaust system, therefore the mechanical vibration of the engine can be passed directly to the exhaust system. Secondly, the random road excitation is passed to the exhaust system through the tires, bodywork and engine. Automobile exhaust system is one of the most important factors that affect the performance of automotive noise, vibration and harshness (NVH). Vibration energy of the exhaust system is transmitted to the underbody by suspension device so that the vehicle's body vibration and noise is generated. Therefore, the research on the vibration characteristics of automobile exhaust systems has very important significance in terms of reducing the overall automobile vibration. Many reports on the noise analysis, back pressure analysis and emission analysis of automobile exhaust system appeared in the relevant literature. There have been only a few researches on dynamic analysis and reliability analysis of the exhaust system. Modeling the exhaust system is the premise regarding the analysis of the exhaust system dynamics. Many scholars have done a great deal of research on the modeling of the exhaust system. The methods used include Finite Element Analysis (FEA) and Experimental Modal Analysis (EMA) and so on. Reports on the vibration characteristics of automobile exhaust systems analysis are as follows: Liu Jingping et al. [1] conducted the forced vibration and modal analysis of the exhaust system

*Address correspondence to this author at the School of Mechanical and automotive Engineering, Xiamen University of Technology, Xiamen, 361024, P.R. China; Tel: 13459263068; E-mail: xujianmin1020@163.com using finite element software and AVL-EXCITE software. The vibration response of the exhaust system and the vibration transmissibility of the exhaust pipe were obtained. Its vibration coupling characteristics was examined. Shang guan Wen bin et al. [2] established vibration analysis model of the exhaust system including a power train. They conducted the free modal and constraint modal test of the exhaust system and their calculated values were analyzed. They proved the correctness of the exhaust system vibration model. Lu Wang Wei et al. [3] established a three-dimensional model of a diesel exhaust system using software Pro/E and obtained its finite element model using software Hyper Mesh. They conducted the simulation of exhaust system using the finite element software ANSYS and got the modal characteristics for the exhaust system. Harmonic analysis of the exhaust system is conducted on this basis. Liu Ming et al. [4] conducted modal analysis and harmonic response analysis of a vehicle exhaust system using the finite element method. They obtained the natural frequency of the exhaust system and found the Modal nodes by modal analysis. The influence of the suspension vertical stiffness regarding the natural frequency of the exhaust system was obtained. Liu Zhien et al. [5] conducted the static, modal and dynamic analysis of the exhaust system. The results showed that the hanging position designed with the method of Average driving DOF displacement (ADDOFD) is reasonable. The suspension system can meet the force requirements and avoid engine idling excitation frequency. The suspension system can meet the force requirements and can avoid engine idling excitation frequency. It ensured that the force from the hook passed to vehicle was within the design limits. Baoen Tao et al. [6] established the finite element model of automotive exhaust system and conducted modal analysis. He also analyzed several pre-order natural frequencies and obtained several mode shapes of the exhaust system. Based on the modal analysis and the vibration test results of exhaust system, they researched and analyzed the vibration of exhaust systems caused by excitation 
at different engine speeds and the vibration characteristics of the exhaust system. They suggested improvements to the structure in order to provide a reference for improving operational reliability and service life of the exhaust system. Meng Chuan Wei et al. [7] analyzed the vibration characteristics of automobile exhaust systems based on the finite element method. Based on average drive DOF theory, they obtained an optimized layout scheme for the exhaust system's suspension point. Wang Jixian et al. [8] established a finite element model for the exhaust system combining Finite Element Modal Analysis and Modal test analysis. They conducted experimental modal analysis and harmonic response analysis based on the software ANSYS, and test equipment and obtained the first six orders of natural frequencies and mode shapes of the exhaust system. Houxian Jun [9] established a finite element model of a car's exhaust system and conducted static calculation and modal analysis. Statics results showed that the force of the vehicle's exhaust system at each suspension rubber was relatively uniform and that the maximum displacement and stress on the system met the design requirements. Modal analysis results showed that at idle and economy speed excitation frequency of the engine could avoid the natural frequencies of the exhaust system, so that the system could have good dynamic characteristics. The influence of temperature on the measured modal parameters of the exhaust system was researched [10]. The systematic FEA study of exhaust system for passenger car was summarized in paper [11]. Yuan SL et al. [12] established a finite element model of the automobile exhaust systems and conducted a modal analysis. The results showed that the stiffness of the suspension system affects the exhaust system modal. He $\mathrm{H}$ et al. [13] conducted a modal testing for a medium-sized bus' exhaust system using the testing software LMS in a test lab and obtained the modal frequencies and mode shapes. Some analysis and estimates were made to the dynamic properties of the exhaust system. Liu H J et al. [14] established the exhaust system model and conducted finite element analysis. They researched the relationship between the hanging position and amplitude. The studies indicated that a change in the hanging position could reduce the maximum amplitude of the exhaust system.

In this paper, the vibration characteristics of an automobile exhaust system is analyzed using finite element software and the suspension points of exhaust system are optimized using an average driving DOF displacement (ADDOFD) method in order to find the optimal mounting points location.

\section{MODAL ANALYSIS THEORY}

Modal analysis is a resolution analysis and experimental analysis of structural dynamics. The dynamic characteristics of the structure are expressed by modal parameters. Modal parameters can be defined as eigenvalues and eigenvectors of differential equations of motion for mechanical systems. Its physical meaning is the system of natural frequencies and mode shapes that are experimentally measured. In this paper, modal analysis is used to obtain the natural frequencies of automotive exhaust systems. The free vibration equation is mentioned as follows.

$[M]\{\ddot{u}\}+[K]\{u\}=\{0\}$

where $[K]$ is the stiffness matrix, $[M]$ is the mass matrix, $\{\ddot{u}\}$ and $\{u\}$ are the acceleration vectors and the displacement vector. The algebraic equation of Natural frequency is obtained by solving the equations of free vibration.

$w^{2 n}+a_{1} w^{2(n-1)}+\cdots+a_{n} w^{2 n}+a_{n}=0$

Each order natural frequency and modal shape of structure can be obtained by solving the equation (2).

\section{METHOD OF AVERAGE DRIVE DOF DISPLACEMENT (ADDOFD)}

Based on the modal analysis theory of multi-DOF system, the function of frequency response between the response point $l$ and the excitation point $p$ are as follows [15].

$H_{l p}(\omega)=\sum_{r=l}^{N} \frac{\phi_{l r} \phi_{p r}}{M_{r}\left(\omega_{r}^{2}-\omega^{2}+j 2 \zeta \omega \omega_{r}\right)}$

where $\phi_{l r}$ is the $r$ order modal shape coefficient of the measurement point $l . M_{R}$ and $\zeta_{r}$ are modal mass and modal damping ratios respectively. If the frequency of the excitation force is $\omega_{r}$, the following approximate equation is used:

$H_{l p}(\omega) \approx \frac{\phi_{l r} \phi_{p r}}{j M_{r} 2 \zeta_{r} \omega_{r}^{2}}$

For linear systems, the amplitude of displacement response is proportional to the amplitude of frequency response function.

$X\left(\omega_{R}\right) \propto H_{l p}(\omega) \approx \frac{\phi_{l r} \phi_{p r}}{j M_{r} 2 \zeta_{r} \omega_{r}^{2}}$

Assuming the modal mass matrix normalizes, modal damping becomes approximately equal to each other, as a result we have:

$X\left(\omega_{R}\right) \propto \frac{\phi_{l r} \phi_{p r}}{\omega_{r}^{2}}$

Average drive DOF displacement of the $\mathrm{j}$-th DOF can be defined as follows.

$A D D O F D(j)=\sum_{r=1}^{N} \frac{\phi_{j r}^{2}}{\omega_{r}^{2}}$

The displacement response of DOF in the general excitation case can be obtained from equation (7). The suspension position of the exhaust system can be optimized by this method.

\section{FINITE ELEMENT MODAL ANALYSIS OF THE AUTOMOTIVE EXHAUST SYSTEMS}

\subsection{Establishment of the Finite Element Model for Automobile Exhaust System}

Automobile exhaust system typically includes the following five parts: three-way catalytic converter, bellow, master muffler, vice muffler and connecting pipes between the various components. Fig. (1) shows the geometry of a 
car's exhaust system. Without prejudice to the premise of solving accuracy, the geometric model is simplified in order to improve the operational efficiency. For example, some fillets, chamfers and holes are removed. The elastic modulus of the material for the exhaust system $E=2.04 e^{11} \mathrm{~Pa}$; Poisson's ratio $\mu=0.285$, density $\rho=7.93 e^{-3} \mathrm{~g} / \mathrm{mm}^{3}$. Threedimensional geometric model of the exhaust system are imported into the software ANSYS to carry on the grid division. The whole finite element model is divided into 29,540 units. The finite element model of exhaust system is shown in Fig. (2).

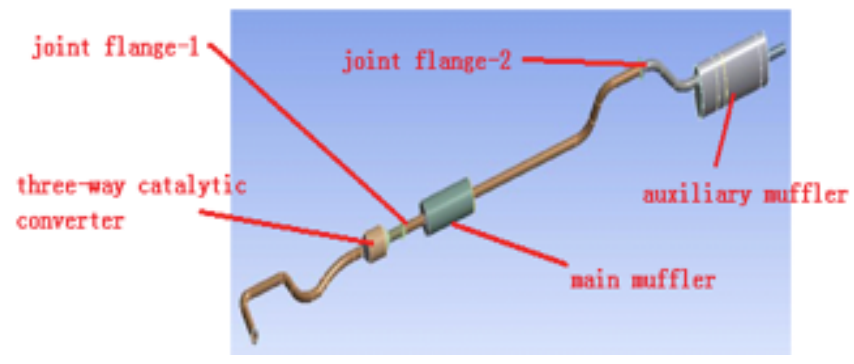

Fig. (1). Geometry of the exhaust system.

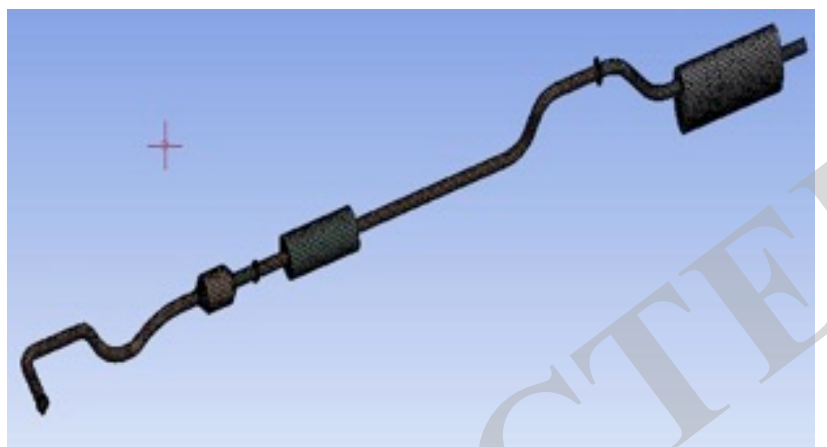

Fig. (2). Finite element model of the exhaust system.

\subsection{Finite Element Modal Analysis of Automotive Exhaust System}

Modal analysis is the key to calculating the exhaust system dynamics. The exhaust system is connected to the engine and vehicle body, therefore, the natural frequency of the exhaust system must be separated from the vibration frequency of the engine and vehicle, otherwise it will produce a strong resonance. In this paper, freedom modal analysis, partially restrained modal analysis and whole constrained modal analysis of the exhaust system have been conducted. The free modal analysis does not consider the influence of exhaust system hanger and exhaust manifold constraints on the exhaust system vibration. Partially constrained modal analysis only considers the impact of exhaust manifold restraint on system vibration. The fully constrained modal analysis takes into account the impact of all constraints on the exhaust system vibration. The first 10 order modal frequencies of system on the three kinds of modal conditions are shown in Table 1. Seen from Table 1: the first of the third natural order frequencies of the exhaust system are very small. With the increase of the modal order, the natural frequency of exhaust system on the three kinds of modal conditions tends to increase. In the same modal order, the natural frequencies on fully constrained modal conditions are higher than the frequencies on partial constrained modal condition and freedom modal condition. Constraints have an important influence on the vibration characteristics of the exhaust system.

The first-order vertical bending modal and the first-order transverse bending modal are mainly considered when analyzing the modal of exhaust system. Because these two modal of the exhaust system become excited more easily by the engine and the vibration of these two modals is easily transmitted to the vehicle body it is easy to produce resonance. Thus, the two modal frequencies must be staggered with the excitation frequency of engine and the natural frequency of the vehicle body. In the present study, the excitation frequency of the engine exhaust system $f=i n / 30 \tau$, where $i$ is the number of cylinder, $n$ is the speed of engine crankshaft, $\tau$ is the number of the engine stroke. Therefore, the excitation frequency in idling condition of the engine $(n=750 \mathrm{r} / \mathrm{min})$ is $25 \mathrm{~Hz}$ and the excitation frequency in economic condition of the engine $(n=3000 \mathrm{r} / \mathrm{min})$ is $100 \mathrm{~Hz}$. The excitation frequency corresponding to the two speeds are different from the natural frequency of the calculation, therefore, it can avoid the resonance between the engines and exhaust system.

Table 1. The first 10 order modal frequencies of exhaust system on the three kinds of modal conditions/Hz.

\begin{tabular}{|c|c|c|c|}
\hline $\begin{array}{c}\text { Modal } \\
\text { Order }\end{array}$ & $\begin{array}{c}\text { Free } \\
\text { Modal }\end{array}$ & $\begin{array}{c}\text { The Modal of } \\
\text { Partially Constraint }\end{array}$ & $\begin{array}{c}\text { The Modal of } \\
\text { Fully Constraint }\end{array}$ \\
\hline \hline 1 & 0 & 0.56383 & 6.9726 \\
\hline 2 & 0 & 0.66528 & 7.1633 \\
\hline 3 & $8.9489 \mathrm{e}-003$ & 5.974 & 50.79 \\
\hline 4 & 0.15748 & 6.7336 & 54.188 \\
\hline 5 & 0.17392 & 13.334 & 64.329 \\
\hline 6 & 4.5952 & 16.287 & 86.666 \\
\hline 7 & 7.3035 & 20.773 & 91.929 \\
\hline 8 & 9.4865 & 26.529 & 94.518 \\
\hline 9 & 18.886 & 41.063 & 105.79 \\
\hline 10 & 22.377 & 46.279 & 146.26 \\
\hline
\end{tabular}

The first 8-order modal shapes of automotive exhaust system in the fully constrained condition are shown in Fig. (3). Modal shape can illustrate the relative displacement and distribution of vibration in automotive exhaust system. Fig. (3) shows that the vibration displacement of the distal end of the exhaust system is always small in the different order modal. The relative displacements of each vibration modal are different. The vibration deformation in the rear end of the main silencer and the vice muffler is relatively larger. When determining the position of the suspension point in the automotive exhaust system, each vibration modal of exhaust system should be considered and the suspension points are arranged in the area with small vibration displacement. 
The first Order

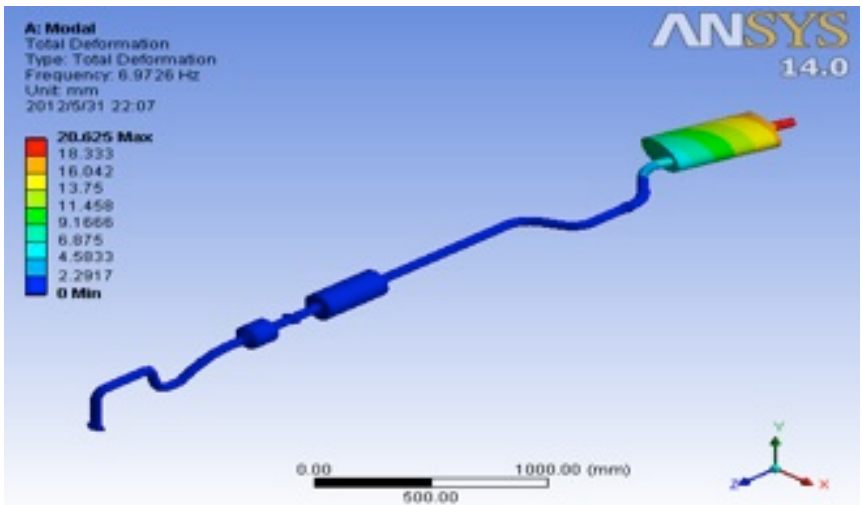

The second order

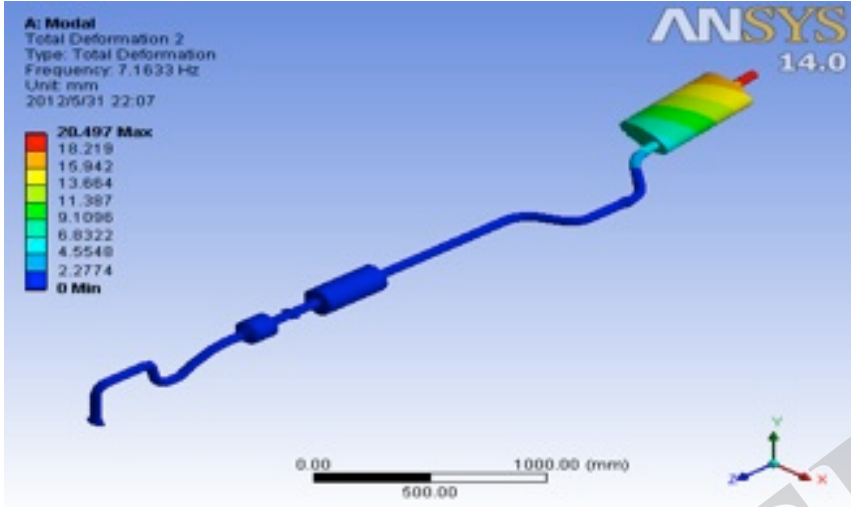

The third order

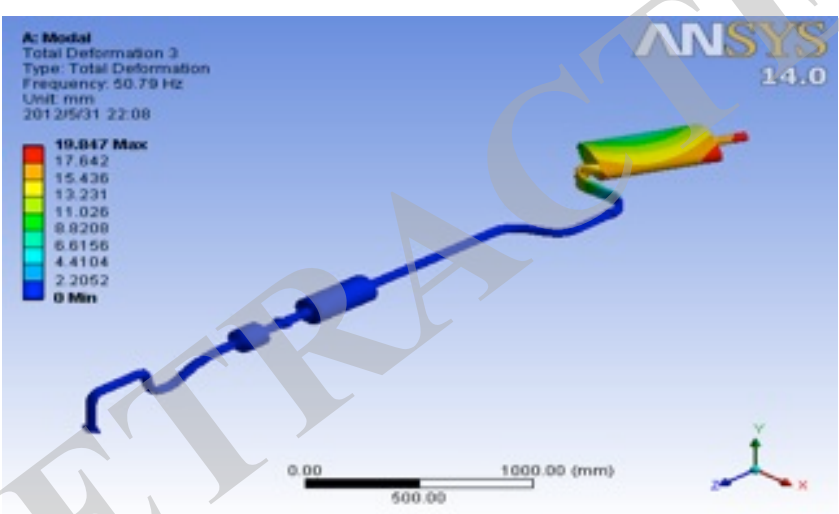

The forth order

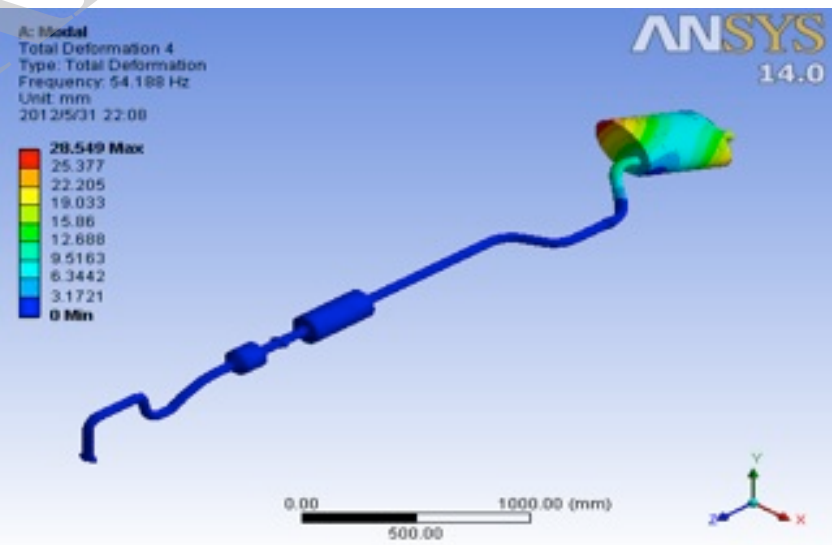

The fifth order

(Fig. 3) contd......

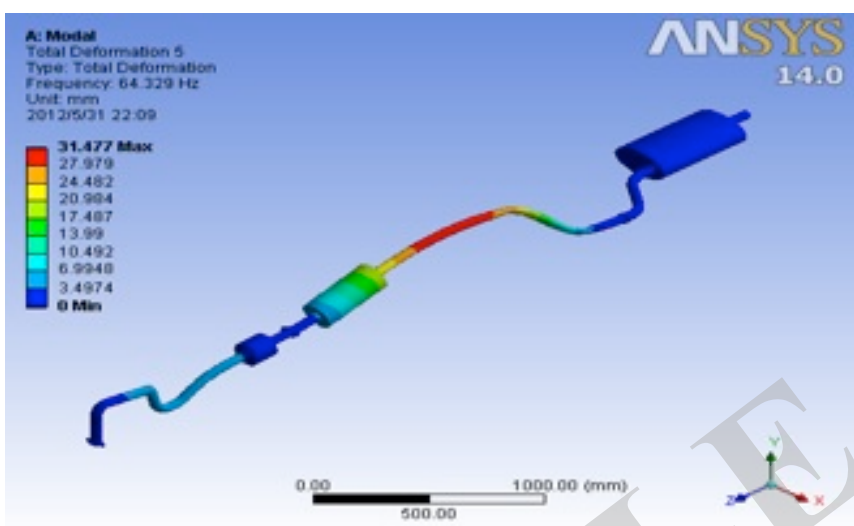

The sixth order

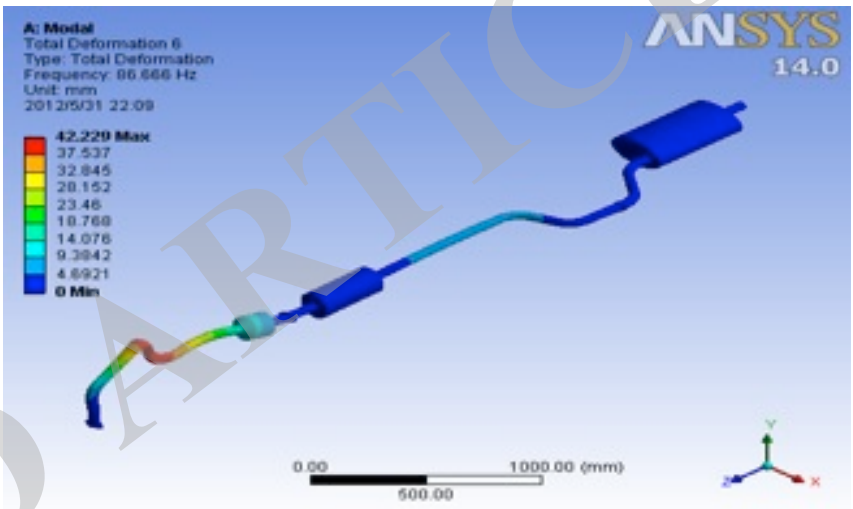

The seventh order

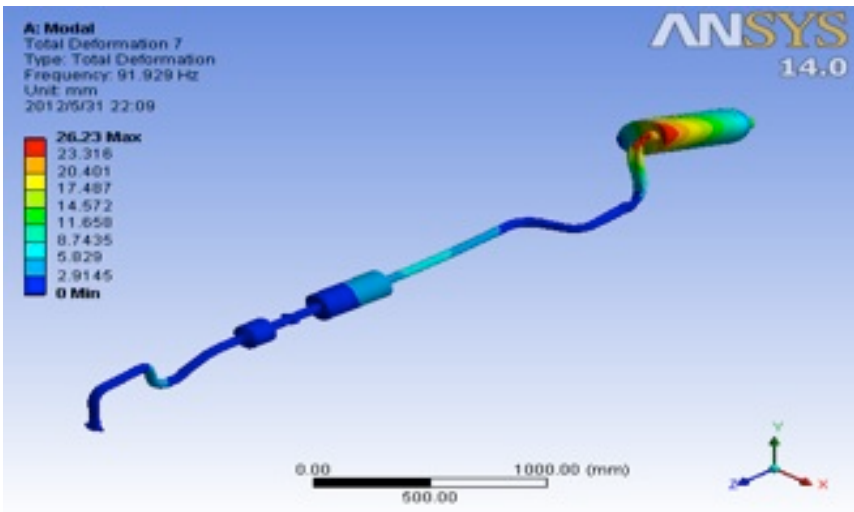

The eighth order

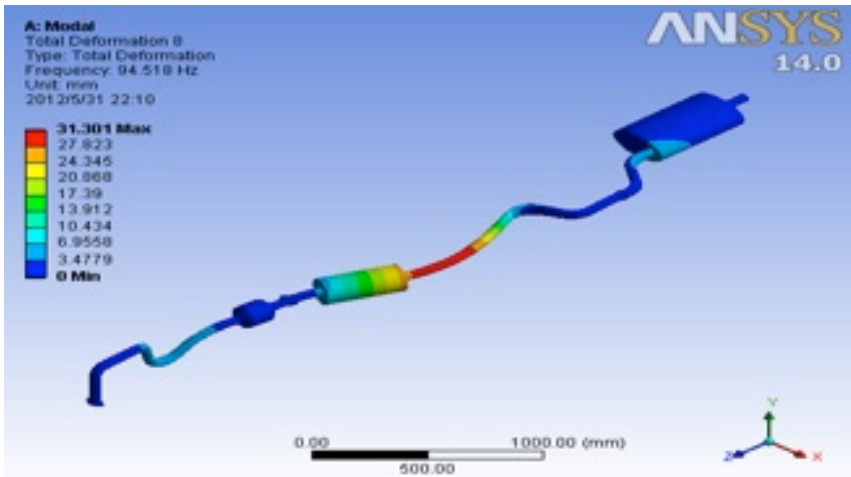

Fig. (3). The first 8-order modal shapes of automotive exhaust system in the fully constrained condition. 


\section{HARMONIC RESPONSE ANALYSIS OF AUTOMOTIVE EXHAUST SYSTEM}

Harmonic response analysis is used to determine the response of the structure withstand the load that changing with the harmonic rule. The harmonic response analysis is used to calculate the structure response under different frequencies and get some response value (it is usually displacement) curve versus frequency. The excitation of the exhaust system is mainly composed of structural vibrations of engine, the high frequency excitation of exhaust and the random vibration caused by road roughness and other factors [16]. In this paper, the vibration of exhaust system caused by engine excitation has been considered mainly regardless of road excitation. The direction of engine excitation and flow direction are the same. Frequency response analysis results of suspension point 1 and 2 are shown in Figs. $(4,5)$ respectively. Figs. $(\mathbf{4}, \mathbf{5})$ show that the vibration amplitudes of exhaust system suspension point becomes smaller and smaller with the increase of the excitation frequency. Lowfrequency band below $140 \mathrm{~Hz}$ should be mainly considered when reducing the noise and vibration of the exhaust system. Thus the vibration amplitude of the engine exhaust system under the condition of low speed is bigger than that under the condition of high speed. The vibration amplitude of suspension point 1 is smaller than that of suspension point 2 . The response curves within the vibration below $140 \mathrm{~Hz}$ show that the peak vibration respectively occurs at $20 \mathrm{~Hz}, 33 \mathrm{~Hz}$, $53 \mathrm{~Hz}, 70 \mathrm{~Hz}, 80 \mathrm{~Hz}, 130 \mathrm{~Hz}$. Maximum peak occurs at $20 \mathrm{~Hz}$ and maximum vibration peak is $2.9 \mathrm{~mm}$.

\section{OPTIMIZATION OF SUSPENSION POINTS FOR AUTOMOTIVE EXHAUST SYSTEM}

Optimization of the exhaust system suspension point is an important method for reducing vibrations and noise based on the view of vibration transfer. The traditional suspension point is selected mainly based on experience or individual modal shape node, thus this method is random. In this paper, the suspension point is optimized based on modal analysis of the exhaust system and the ADDOFD theory. At first, a number of points along the axial of exhaust system are selected as the potential hanging points for the exhaust system. Then the displacement data for the corresponding points in the free modal results file is obtained. A curve is drawn based on the displacement results obtained from the weighted cumulative. Finally, some points with relatively small weighted accumulated displacements (the point near the trough of curve) are obtained as the ideal hook position for the exhaust system.

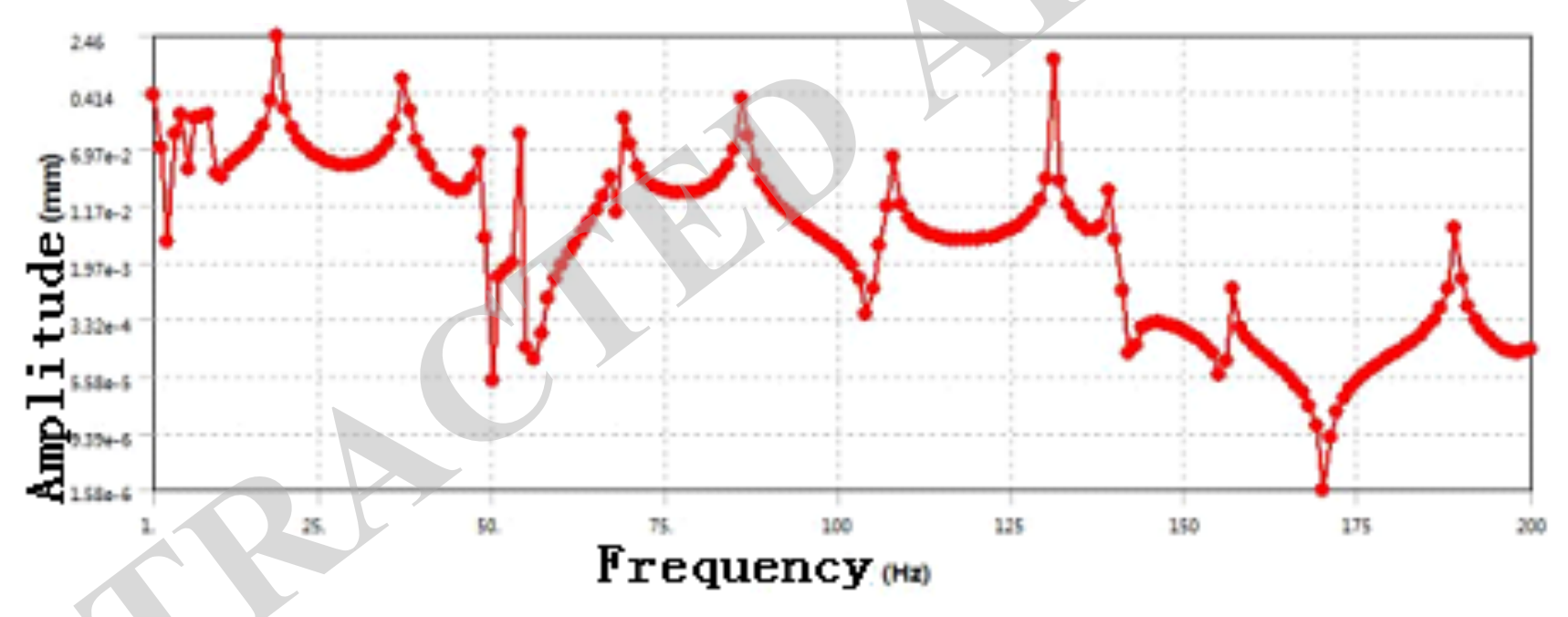

Fig. (4). Characteristic of displacement frequency response for suspension point 1.

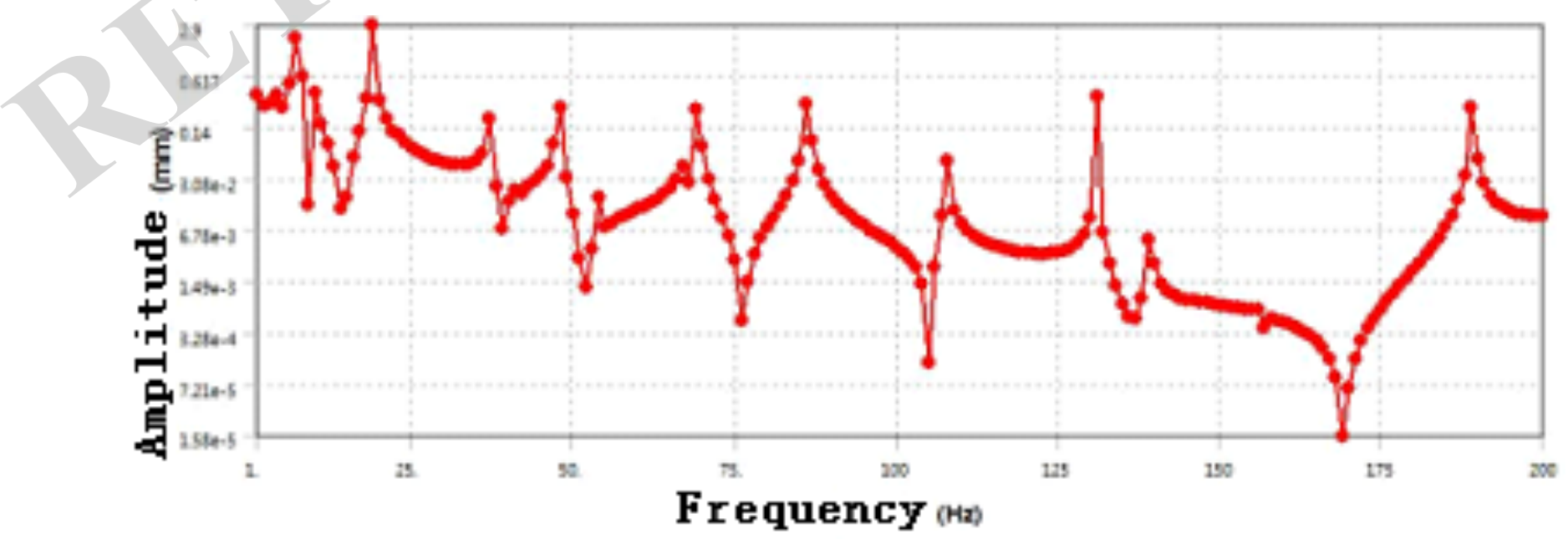

Fig. (5). characteristic of displacement frequency response for suspension point 2. 


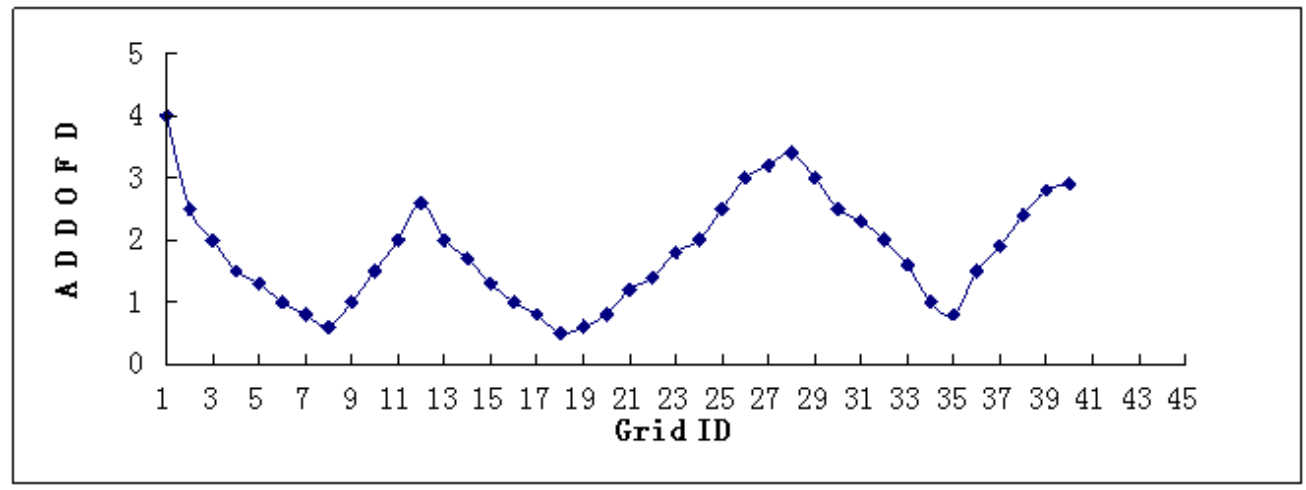

Fig. (6). Average drive DOF displacement of the exhaust system.

Based on the ADDOFD theory, the average drive of DOF displacement curve of the vertical exhaust system is shown in Fig. (6). Wherein the abscissa represents the identification of potential suspension points of the exhaust system (Grid ID), ordinate represents the values of average driving DOF displacement (ADDOFD). According to the ADDOFD theory, the average driving DOF displacement curve reflects vibration patterns of the exhaust system in the range of analysis frequency. It can be seen from Fig. (6) that there are some minimum points in the curve. The vibration amplitude of the exhaust system parts corresponding to these points is small and the vibration energy transmitted to the vehicle is the minimum. These points are the best choice for choosing the suspension point for the exhaust system. The real parts of the exhaust system corresponding to these points are shown in Fig. (7). Position 1, 2 and 3 are exhaust system suspension points of the best location.

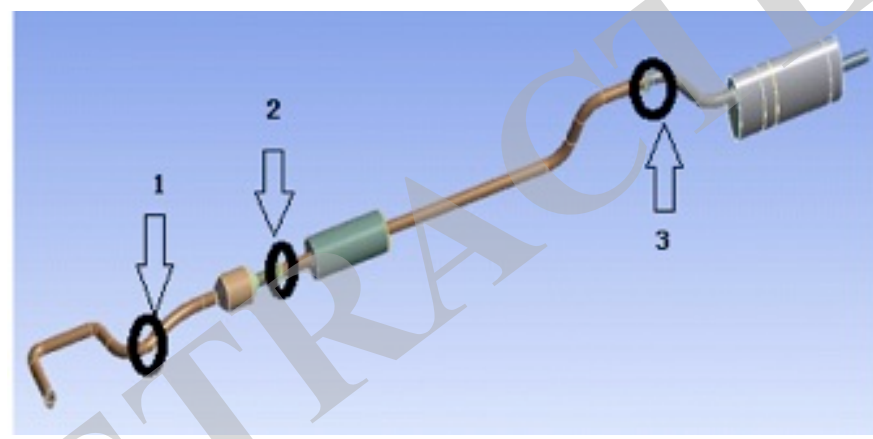

Fig. (7). Optimal placement of the suspension points obtained according to ADDOFD results.

\section{CONCLUSION}

A finite element model for car's exhaust system is established and modal analysis of the exhaust system is conducted. The natural frequencies and modal shapes of the exhaust system are obtained. The natural frequency of the exhaust system is relatively low. It indicates that the stiffness of overall structure is small and the first few modal frequencies are very close. The modal shapes of the exhaust system mainly include the swing vibration and torsion vibration modal. The study provides a theoretical basis for avoiding the resonance because the excitation frequency of the engine approaches the natural frequency of the exhaust system.
(2) The vibration response of the exhaust system is mainly in the low frequency band. The vibration amplitude of the suspension point is large when the exhaust system is inspired under the excitation below $140 \mathrm{~Hz}$. The vibration amplitude of the engine exhaust system under the condition of low speed is bigger than that under the condition of high speed.

(3) The average drive DOF displacement curve of the exhaust system is obtained based on the average drive DOF displacement theory. The optimized suspension points of the exhaust system are obtained. These points can effectively prevent vibrations of the exhaust system from transmitting to the vehicle's body. It provides insights for the selection of suspension point of exhaust system.

\section{CONFLICT OF INTEREST}

The authors confirm that this article content has no conflict of interest.

\section{ACKNOWLEDGEMENTS}

This paper is supported by the National Natural Science Foundation of China (Grant No.51375411; 51205336) and the Natural Science Foundation of Fujian Province (Grant No.2013J05086).

\section{REFERENCES}

[1] J. Liu, B. Deng, B. Du, R. Feng, S. Xu, "Vibration analysis on car's exhaust system," J. Vib. Shock, vol. 30, no. 8, pp. 237-242, Aug. 2011.

[2] W. Shangguan, Z. Huang, L. He, X. Duan, "Modeling and optimization method of dynamic stiffness for automotive exhaust system hangers," J. Vib. Shock, vol. 29, no. 1, pp. 100-102, Jan. 2010.

[3] Hongwei Lu, Zhenlin Ji and Ruixue Meng, "Numerical simulation and analysis of vibration characteristics for diesel engine exhaust system," Noise Vib. Cont., vol. 32, no. 3, pp. 41-44, Jun. 2012.

[4] M. Liu, J. Weng, "Vibration investigation of exhaust system and optimization of hangers' location," Noise Vib. Cont., vol. 30, no. 5, pp. 95-97, Oct. 2010.

[5] Z. Liu, J. Tian, Y. Wu, J. Houxian, J. Li, "Hanger location layout of automotive exhaust system," J. Wuhan Univ. Tech.: Inform. Manag. Eng., vol.32, no. 6, pp. 950-953, Dec. 2010

[6] E. Bao, Y. Lu, "Vibration characteristics of a vehicle exhaust system," Noise Vib. Cont., vol. 32, no. 5, pp. 101-103, Oct. 2012.

[7] C. W. Meng, X. Xia, "Automobile Exhaust System's Vibration Characteristic Analysis and Hanger Location Optimization," Mach. Elect., vol. 26, no. 5, pp. 24-27, May. 2013.

[8] J. Wang, Z. Li, W. Wang, Q. Zheng, L. Chen, "Vibration Characteristic Analysis of Engine Exhaust System," Chinese Intern. Combust. Engine Eng., vol. 29, no. 3, pp. 72-75, Jun. 2008. 
[9] J. Houxian, Z. Liu, F. Yan, "Statics Calculation and Modal Analysis of Automotive Exhaust System," Automot. Tech., vol. 24, no. 1, pp. 40-42, Jan. 2010.

[10] G. Iyer, S. Mohan, N. Rao, S. Unnithan, "Evaluation of Dynamic Characteristics of an Automotive Exhaust System using Operational Modal Analysis (OMA) and Experimental Modal Analysis (EMA)," SAE Technical Paper, vol. 29, no. 4, pp. 55-61, Aug. 2013.

[11] S. Rajadurai, N. Suresh, "Systematic FEA Study of Passenger Car Exhaust System Using Radioss," SAE Technical Paper, vol. 27, no. 8, pp. 95-104, Aug. 2011

[12] S. L. Yuan, W. C. Zhang, Z. E. Liu, C. Wang, D. Y. Fu, "Research on Influence of Flexible Parts' Rigidity to Passenger Car Exhaust System's Modal," Appl. Mech. Mat., vol. 117, no. 4, pp. 141-145, Apr. 2012
[13] H. He, H. Zhou, S. L. Wang, "Modal Testing Analysis and Dynamic Properties Estimate on the Exhaust System of a MediumSized Bus," Appl. Mech. Mat., vol. 224, no. 8, pp. 146-150, Oct. 2012.

[14] H. J. Liu, S. Y. Zhi, "Exhaust System Finite Element Analysis and Optimizing Design, “Adv. Mat. Res., vol. 538, no. 9, pp. 590-594, Dec. 2012.

[15] Y. Tian, J. Liu, "Vibration modal analysis and hanger location optimization of automobile exhaust system," J. Liaoning Tech. Univ. (Nat. Sci.), vol. 28, no. 6, pp. 995-998, Dec. 2009.

[16] X. Zhang, Y. Wang, Z. Pan, et al, "Analysis of exhaust system hanger locations layout based on MSC. Nastran," J. Hefei Univ. Tech. (Nat. Sci.), vol. 32, no. 12, pp. 116-124, Dec. 2009.

(C) Xu et al.; Licensee Bentham Open.

This is an open access article licensed under the terms of the Creative Commons Attribution Non-Commercial License (http://creativecommons.org/licenses/by-nc/3.0/) which permits unrestricted, non-commercial use, distribution and reproduction in any medium, provided the work is properly cited. 